\title{
O sentido olfatório na Artrite Idiopática Juvenil
}

\author{
Caroline C. Gomes (IC), Fernando A. Peres (PG), Nailú A. Sinicato(PG), Karina O. Peliçari (PG), \\ Mariana Postal (PG), Roberto Marini (PQ), Maraisa Centeville (PQ), Simone Appenzeller (PQ).
}

\section{Resumo}

Nos últimos anos tem crescido as evidências da inter-relação entre o sistema imunológico e o sistema nervoso central (SNC), em especial o sistema olfativo. Em doenças autoimunes, como o Lúpus Eritematoso Sistêmico, observou-se que a disfunção olfatória estava associada a depressão, ao declínio cognitivo e a atividade da doença. Porém não existem estudos na Artrite Idiopática Juvenil (AlJ). O objetivo do trabalho é determinar a prevalência de distúrbios olfatórios no AIJ.

Palavras Chave: Artrite Idiopática Juvenil, Transtornos de Humor, Sentido Olfatório.

\section{Introdução}

A artrite idiopática juvenil (AIJ) é uma das doenças reumatologias mais frequentes na infância. Acomete preferencialmente as pequenas articulações, em alguns casos pode ter manifestações sistêmicas como febre e serosite. Embora relativamente benigna, alterações do humor e implicações na qualidade de vida são frequentemente observadas. Estudos recentes observaram ligações entre o sistema olfatório, o sistema imune e o sistema límbico em doenças autoimunes. A diminuição do olfato foi observada em pacientes com doenças do SNC nas quais mecanismos imuno-mediadores, por exemplo, doença de Parkinson, esquizofrenia, doença de Alzheimer e esclerose múltipla. Porém a alteração do olfato não foi estudada na AIJ.

\section{Resultados e Discussão}

A função olfativa de pacientes e controles foi avaliada pelo teste de Sniffin Sticks, composto por 3 fases: discriminação, limiar e identificação de odores diferentes. Transtornos de humor foram determinados através do inventário de Depressão de Beck (BDI) e Inventário de Ansiedade Beck (BAI). Foram incluídos 42 pacientes com AlJ e 43 controles pareados por sexo e idade. Os pacientes tiveram uma média de 29,40 $\pm 7,75$ pontos totais nas 3 fases de teste Sniffin 'Sticks, enquanto os controles tiveram média de 31,27 \pm 5,35 pontos $(p>0,05)$. O sentido olfatório normal foi observado em 14 (33,3\%) dos pacientes e 27 $(62,7 \%)$ controles $(p<0,05)$. Hiponosmia foi observada em 24 (57\%) pacientes 13 (30\%) controles $(p<0,05)$ e anosmia em $4 \quad(9 \%)$ pacientes e 3 (6\%) controles $(p>0,05)$. Observamos correlação entre os escores totais (soma das 3 fases) com depressão $(r=0,3, p$ $<0,01)$ e ansiedade $(r=0,4, p=0,001)$. 0

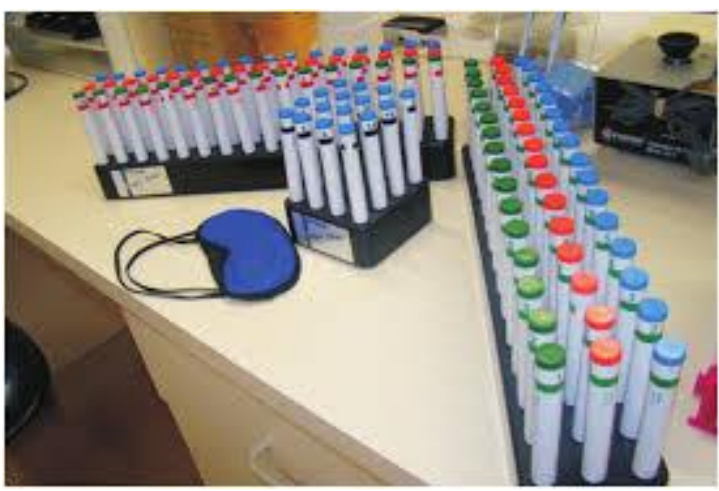

Figura 1. Teste Sniffin Sticks

\section{Conclusões}

Encontramos uma diminuição significativa do sentido olfatório olfato nos pacientes com AIJ. A diminuição do olfato se correlacionou com alterações do humor. É necessário correlacionar esta alteração também com a atividade da doença.

\section{Agradecimentos}

Agradeço a todos que participaram da realização deste projeto.

\footnotetext{
1. C Modesto, J Antón, B Rodriguez, R Bou, C Arnal, J Ros, X Tena, C Rodrigo, eu Rotés, E Hermosilla, e P Barceló

Scandinavian Journal of Rheumatology $201039: 6$, 472-479.

2. DN Vidro, EH Giannini.Artrite reumatóide juvenil como um traço genético complexo.Arthritis Rheum, 42 (1999), pp 2261-2268.

3. Berent Prakken, Salvatore Albani, Alberto Martini, artrite idiopática juvenil, The Lancet, Volume 377, Issue 9783, 18-24 junho 2011, Pages 2138-2149, ISSN 0140-6736, 10.1016/S0140-6736 (11)

4. Woo P ,Colbert RA. Uma visão geral da genética de doenças reumáticas pediátricas. Melhor Res Clin Pract Reumatol . 2.009; 23 (
} $60244-4$. 5 ): $589-597$ 